\title{
The analysis of the relationship among emotional intelligence, organizational deviance, quality of work life and turnover intentions in hospitality business
}

\author{
Mahmut Demir $^{1}$
}

Received: 27/02/2011

\begin{abstract}
${ }^{1}$ Mugla University, Mugla, Turkey, Phone: +90 252 2111871, e-mail: mdemir1@gmail.com
Supervisor: Prof. Ozkan Tutuncu, Dokuz Eylul University, Izmir, Turkey

Institution awarding the Ph. D. Degree: Dokuz Eylul University, Izmir, Turkey

Date of defence: $04^{\text {th }}$ August 2010

(C) 2011 International University College. All rights reserved

Citation: Demir, M. (2011), The analysis of the relationship among emotional intelligence, organizational deviance, quality of work life and turnover intentions in hospitality business. Doctoral dissertation summary. European Journal of Tourism Research 4(2), pp. 214-216
\end{abstract}

\section{Goal and objectives of the dissertation \\ Goal}

The main goals of the research are 1) to analyze the relationship between emotional intelligence, organizational deviance, and quality of work life, and 2) to determine their effects on turnover intentions. In order to reach these goals, first, a conceptual model has been determined. The first factor, emotional intelligence, represents the external variables, but organizational deviance, quality of work life, and turnover intentions represent internal variables.

\section{Objectives}

There are three objectives of this dissertation. The first is to understand the direct relationship between emotional intelligence and internal variables. The second objective is related to analysis between relationship three variables (emotional intelligence, organizational deviance, and quality of work life) and turnover intention without mediating role. The third is to 214 analyze quality of work life moderates the effect of emotional intelligence on turnover intention.

\section{Methodology}

This research has four different dimensional structures and the measures are developed from prior research in different models. Questionnaire of all dimensions has 43 items to measure respondents' attitudes in four parts. Emotional intelligence is measured by twelveitems from the scale developed by MSCEIT, EQ-I, and ECI models which are based on one used by Mayer, Salovey \& Caruso (2004), BarOn (2005; 2003) and Goleman (1998). Organizational deviance is measured by twelve-items from the scale developed by Hollinger \& Clark (1982), Robinson \& Bennett (1995), and Lawrence \& Robinson (2007). Quality of work life is measured by twelve-items from the scale developed by Walton (1975), B. Gilbert (1989), and Sirgy, Efraty, Siegel \& Lee (2001). Turnover intention is measured by fouritems from the scale developed by Arnold \& DOCTORAL DISSERTATION 
Davey (1999), and Tutuncu \& Demir (2002). The scale is adapted into Turkish and respondents answered on a five-point Likert type scale (ranging from $1=$ strongly disagree to $5=$ strongly agree). Through conducting a faceto-face interview with the employees of five-star hotels in south-west coast of Turkey, of the 596 responses received, 563 provided answers to all questions. LISREL 8.80 is used to analyze the relationship among emotional intelligence, organizational deviance, quality of work life, and turnover intention for research hypotheses within structural equation modelling.

\section{Results}

The findings indicate a significant relationship between internal and external factors. In this context, emotional intelligence, as an external factor, has a significant positive influence on decreasing employees' deviant behaviour. It means that this factor is negatively associated with organizational deviance. While this factor has a significant and positive influence on quality of work life, on the other hand, it has a significant negative influence on turnover intention. Thus, hypothesis related to emotional intelligence are supported. The findings indicate that there is a relationship between quality of work life and organizational deviance as well as turnover intention. The perceived quality of work life has a negative effect on organizational deviance as increasing employees' quality of working and social life. This research shows that this factor has a strong negative association with employees' deviant behaviour and high correlations are found between these two variables. Similarly, quality of work life has a significant and negative influence on turnover intention. As a result, hypothesis related to quality of work life are supported. Finally, organizational deviance is strong and positively associated with turnover intention. The results indicate that organizational deviance has a significant influence on turnover intention. Hypothesis related to organizational deviance is supported.

\section{Theoretical conclusions}

The recent researches show that the emotional intelligence has a crucial role with associated various organizational behaviour issues and it is increasingly relevant to organizational development and employees' standard of living. Emotional intelligence approach provides a new way to understand employees, and also assess positive organizational climate because of good communication skills, their behaviours, and attitudes. Emotional intelligence is also an important consideration in quality of work life which contributes increasing quality of work life, contrasting the decreasing deviant behaviour of employees as well as turnover intentions. The outcomes of quality of work life has positive effect on employees' job satisfaction, commitment to organization, reducing job stress, conflict, improving interpersonal relationships, and increasing stability, harmony and trust to prevent or reduce organizational deviance and turnover intentions.

\section{Practical application of the dissertation}

The findings indicate that emotional intelligence is a key factor to create a suitable working environment in organizations. There are four dimensions of external factor as emotional perception, emotional facilitation of thought, emotional understanding, and emotional management (MSCEIT). Emotional management has the highest percentage of variance explained in external factor and has most important role in relation emotional intelligence and others, because the regulation of emotion in self and others. Similarly, other dimensions have also an important role in this factor. The use of emotional intelligence in organizations has an impact on employees' expectations for future outcomes. On the other hand, it provides to improve quality of work life for the employees' satisfaction with their worklife balance. Both emotional intelligence and high quality of work life play a crucial role in decreasing employees' deviant behaviour as organizational deviance and interpersonal deviance. Both factors have a stronger negative influence on interpersonal deviance, such as showing favouritism, gossiping about co-workers, blaming co-workers, sexual harassment, verbal abuse, stealing from coworkers, than organizational deviance, such as leaving early, taking excessive breaks, intentionally working slow, sabotaging equipment, lying about hours worked and stealing from company. The two sub-factors, job design and promotion, of quality of work life 

intentions in hospitality business. Doctoral dissertation summary.

have stronger influence on decreasing interpersonal deviance while third sub-factor, ergonomic, has stronger on organizational deviance. Finally, turnover intention is affected by each factor. The findings indicate that the most important factor negatively affecting on turnover intention is emotional intelligence. But, interpersonal deviance has a stronger positively affecting on turnover intentions. As a result, there is a relationship among emotional intelligence, organizational deviance, quality of work life and turnover intentions.

\section{Content of the dissertation}

\section{Abstract of chapter one}

The first chapter includes the literature review related to emotional intelligence, organizational deviance, quality of work life and turnover intentions. This chapter is divided into four sections. In the first section, emotional intelligence is presented as conceptual definitions and importance, prior models, and research hypotheses related to emotional intelligence are given based on the literature review. The second section includes conceptual definitions of organizational deviance and its importance in hotels, approaches and dimensions of organizational deviance, and research hypotheses related to organizational deviance. In the third section, quality of work life has been examined conceptually. It includes conceptual definitions and dimensions of quality of work life and its importance in hotels, affecting factors, and research hypotheses. The last section of the first chapter includes turnover intentions.

\section{Abstract of chapter two}

The second chapter includes research methodology, data collecting and the analysis of findings. This chapter is divided into four sections. The first section presents methodology which consists of scales, ranging, items used, etc. The second section presents the terms and places of data collection, determining the respondent and their characteristics. The last section of the second chapter includes the analysis of findings which consist of structural equation modelling and statistical results.

\section{Abstract of chapter three}

Chapter three presents the result by statistically evaluating the relation between variables, and the conclusion and recommendations are also put forward. Correlation estimates, construct means, standardized deviations, properties of the measurement model and results of the research model are indicate in different tables. In conclusion, there is a positive and significantly correlation between emotional intelligence and quality of work life as well as between organizational deviance and turnover intentions. On the other hand, emotional intelligence and quality of work life have negative and significantly correlation with not only organizational deviance but also turnover intentions. The dimension of emotional management of emotional intelligence is found as the most important sub-factor. Job design and promotions is the most important predictor of quality of work life and these variables can prevent employees' deviant behaviour and turnover intentions. Interpersonal deviance, including the political deviance and personal aggression, has negative effects on quality of work life, but its effect on turnover intentions is positive.

\section{Abstract of chapter four}

Chapter four puts forward the concluding remarks as well as implications for the theoretical background, practice, and limitations and future research directions. By evaluating the relationship between the all factors of this study statistical results and important data which can be used in organizational behaviour studies has been reached. The result of this study not only is important for employees, managers and supervisor but also constitutes an important resource for tourism researcher and hotel business. Future research may consider some significant moderating variables between the external factors and turnover intentions, such as organizational commitment, trust, justice, and support. 